\title{
Role of hyperhomocysteinemia in endothelial dysfunction and atherothrombotic disease
}

\author{
RC Austin ${ }^{\star, 1}$, SR Lentz ${ }^{2}$ and GH Werstuck ${ }^{3}$ \\ 1 Department of Pathology and Molecular Medicine, McMaster University and \\ the Henderson Research Centre, Hamilton, Ontario, Canada \\ 2 Veterans Affairs Medical Center and Department of Internal Medicine, \\ University of lowa, lowa City, IA, USA \\ ${ }^{3}$ Departments of Biochemistry and Medicine, McMaster University, Hamilton, \\ Ontario, Canada \\ * Corresponding author: RC Austin, Henderson Research Centre, 711 \\ Concession Street, Hamilton, Ontario, Canada L8V 1C3. Tel: + 1905527 \\ 2299 ext. 42628; Fax: + 1905575 2646; \\ E-mail: raustin@thrombosis.hhscr.org
}

Received 16.3.04; accepted 24.3.04

Edited by G Melino

\begin{abstract}
Hyperhomocysteinemia (HHcy) is an independent risk factor for cardiovascular disease, including ischemic heart disease, stroke, and peripheral vascular disease. Mutations in the enzymes responsible for homocysteine metabolism, particularly cystathionine $\beta$-synthase (CBS) or 5,10 -methylenetetrahydrofolate reductase (MTHFR), result in severe forms of HHcy. Additionally, nutritional deficiencies in B vitamin cofactors required for homocysteine metabolism, including folic acid, vitamin B6 (pyridoxal phosphate), and/or B12 (methylcobalamin), can induce HHcy. Studies using animal models of genetic- and diet-induced HHcy have recently demonstrated a causal relationship between HHcy, endothelial dysfunction, and accelerated atherosclerosis. Dietary enrichment in B vitamins attenuates these adverse effects of HHcy. Although oxidative stress and activation of proinflammatory factors have been proposed to explain the atherogenic effects of HHcy, recent in vitro and in vivo studies demonstrate that HHcy induces endoplasmic reticulum (ER) stress, leading to activation of the unfolded protein response (UPR). This review summarizes the current role of HHcy in endothelial dysfunction and explores the cellular mechanisms, including ER stress, that contribute to atherothrombosis.

Cell Death and Differentiation (2004) 11, S56-S64.

doi:10.1038/sj.cdd. 4401451
\end{abstract}

Keywords: hyperhomocysteinemia; atherosclerosis; endothelial dysfunction; endoplasmic reticulum stress; apoptosis

\footnotetext{
Abbreviations: apoE, apolipoprotein E; CBS, cystathionine $\beta$-synthase; GADD153, growth arrest- and DNA damage-inducible gene 153; HHcy, hyperhomocysteinemia; elF2 $\alpha$, eukaryotic initiation factor- $2 \alpha$; ER, endoplasmic reticulum; GRP, glucose-
}

regulated protein; MCP-1, monocyte chemoattractant protein 1; MTHFR, 5,10-methylene tetrahydrafolate reductase; PERK, PKR-like ER kinase; ROS, reactive oxygen species; TDAG51, T-cell death-associated gene 51; UPR, unfolded protein response; XBP-1, X-box binding protein-1

\section{Introduction}

Clinical manifestations of atherothrombotic disease, cardiac arrhythmias, myocardial infarction and stroke account for the majority of deaths in North America. ${ }^{1-4}$ Atherothrombosis is a complex, chronic process that is initiated at sites of endothelial cell injury and culminates in atherosclerotic lesion disruption with superimposed thrombus formation. ${ }^{1-5}$ Cholesterol deposition, infiltration of monocytic cells, proliferation and migration of smooth muscle cells, and elaboration of extracellular matrix are characteristic features of atherosclerotic lesions. Cholesterol-enriched macrophages, morphologically recognized as foam cells, are also observed during lesion development. $^{6,7}$ It is well established that the acute clinical manifestations of atherothrombotic disease result from lesion rupture, triggering thrombus formation and vessel occlusion. $^{2,8}$

Apoptotic cell death is a hallmark feature of both animal and human atherosclerotic lesions. ${ }^{9-11}$ Apoptotic cells can be observed throughout advanced atherosclerotic lesions, but are most prominent in and around the lipid-rich core. It has been suggested that apoptosis increases the risk of lesion rupture by decreasing the number of viable smooth muscle cells necessary for collagen production and stabilization of the fibrous cap. Furthermore, apoptosis enhances thrombogenicity by increasing the number of tissue factor-rich apoptotic cells within the atherosclerotic lesion. ${ }^{12,13}$ However, the cellular pathways responsible for this effect and their relevance to atherothrombotic disease are incompletely understood.

Hyperhomocysteinemia (HHcy) is a pathological condition characterized by an increase in plasma concentration of total homocysteine. ${ }^{14-21}$ Numerous clinical and epidemiological studies have indicated that HHcy is an independent risk factor for atherothrombotic disease. Up to $40 \%$ of patients diagnosed with premature coronary artery disease, peripheral vascular disease, or recurrent venous thrombosis present with HHcy. ${ }^{14-19}$ Recent studies have now demonstrated that homocysteine causes endothelial cell dysfunction and induces apoptotic cell death in cell types relevant to atherothrombotic disease, including endothelial cells ${ }^{22,23}$ and smooth muscle cells. ${ }^{24}$ Furthermore, a direct causal relationship between induction of HHcy and accelerated atherosclerosis has been reported in apolipoprotein $E$ (apoE)-deficient mice with diet- and/or genetic-induced HHcy. ${ }^{25-28}$ Given that oral administration of folic acid or a 
combination of $\mathrm{B}$ vitamins can decrease HHcy and attenuate atherogenesis in these animal models, ${ }^{26,28}$ there is growing interest for treatment of $\mathrm{HHcy}$ as a strategy for prevention of atherothrombotic disease.

In this review article, we will summarize the genetic and dietary factors that induce HHcy. In addition, the cellular mechanisms that may explain how HHcy causes endothelial cell dysfunction and accelerates atherosclerotic lesion development will be discussed in light of recent findings in animal models of HHcy.

\section{Genetic and Nutritional Factors that Induce HHcy}

Homocysteine is a thiol amino-acid synthesized during the metabolic conversion of methionine to cysteine. Once generated, homocysteine is either metabolized to cysteine via the transsulfuration pathway or remethylated to methionine via the remethylation pathway (Figure 1). ${ }^{17,20,21}$ Mutations in genes responsible for the metabolism of homocysteine, including cystathionine $\beta$-synthase (CBS), methionine synthase (MS), 5,10-methylenetetrahydrofolate reductase (MTHFR), or betaine homocysteine methyltransferase (BHMT), can result in severe forms of $\mathrm{HHcy}$, termed homocystinuria. The most common genetic cause of homocystinuria, homozygous CBS deficiency, results in plasma total homocysteine concentrations of up to $400 \mu \mathrm{mol} / \mathrm{l}$, compared to normal levels of $10-12 \mu \mathrm{mol} /{ }^{17,21} \mathrm{CBS}$ deficiency is associated with a wide range of clinical manifestations, including mental retardation, ectopia lentis, osteoporosis, skeletal abnormalities and hepatic steatosis. ${ }^{17}$

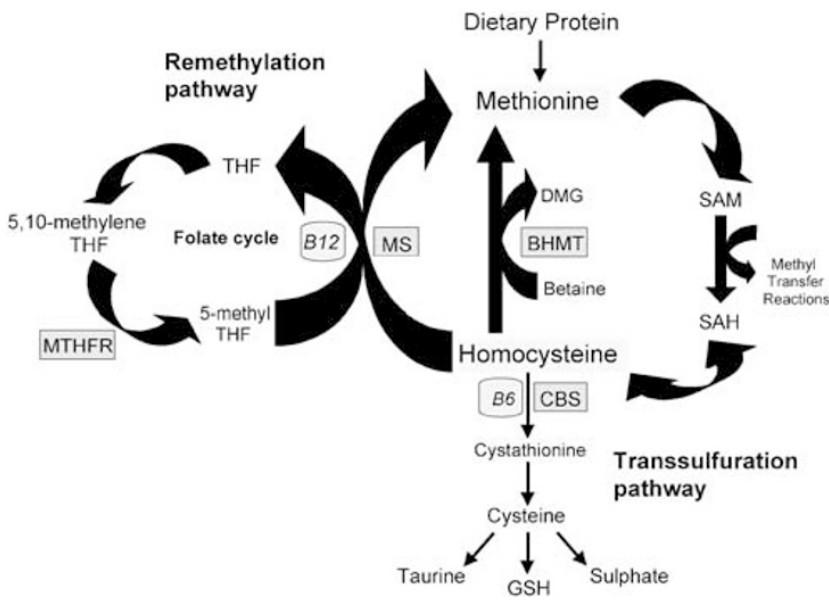

Figure 1 Homocysteine metabolic pathways. Dietary methionine is converted to the methyl donor $S$-adenosylmethionine (SAM) and is demethylated to $S$ adenosylhomocysteine (SAH) and homocysteine. In the transsulfuration pathway, homocysteine is converted to cystathionine by the enzyme cystathionine $\beta$ synthase (CBS) and the cofactor vitamin B6 (pyridoxyl phosphate). Once formed from cystathionine, cysteine can be utilized in a number of cellular functions, including protein synthesis and glutathione (GSH) production. Homocysteine can also be remethylated through the folate cycle. This pathway requires the enzyme methionine synthase (MS) and vitamin B12 as well as the enzyme 5,10methylenetetrahydrofolate reductase (MTHFR) and folic acid, which enters the cycle as tetrahydrofolate (THF). In liver and kidney, homocysteine is also remethylated by the enzyme betaine homocysteine methyltransferase (BHMT) which transfers a methyl group to homocysteine via demethylation of betaine to dimethylglycine (DMG)
Furthermore, patients are at high risk for cardiovascular disease, which is the major cause of death. ${ }^{29-31}$ Although homozygous CBS deficiency is rare, the incidence of heterozygous CBS deficiency may be found in up to $1 \%$ of the general population and is associated with premature cardiovascular disease in phenotypically normal individuals. ${ }^{29-31}$ Deficiency of MTHFR causes severe HHcy and can lead to premature atherosclerosis and thrombotic disease. ${ }^{32-34}$ Renal insufficiency or nutritional deficiencies of $B$ vitamins required for homocysteine metabolism, namely folic acid, vitamin B6 (pyridoxal phosphate), and/or vitamin $\mathrm{B} 12$ (methylcobalamin), also cause HHcy. ${ }^{35,36}$ It is estimated that inadequate intake of vitamins accounts for two-thirds of all cases of HHcy. ${ }^{36}$ Although vitamin supplementation has been shown to be effective in lowering plasma homocysteine levels, it remains to be determined if the risk of cardiovascular disease is decreased.

\section{HHcy and Endothelial Cell Dysfunction}

The term 'endothelial dysfunction' refers to impairment of the normal homeostatic properties of vascular endothelium, which include endothelium-dependent regulation of vascular tone, hemostasis, and inflammation. ${ }^{37}$ Endothelial dysfunction is commonly detected as impairment of endotheliumdependent relaxation of blood vessels, and is predictive of adverse cardiovascular outcomes. ${ }^{38}$ Many studies using animal models and human subjects have demonstrated that HHcy induces endothelial dysfunction. ${ }^{39,40}$ The degree of impairment of endothelium-dependent relaxation during HHcy is similar to that of other risk factors such as hypercholesterolemia and hypertension. ${ }^{39}$

The mechanisms by which HHcy induces endothelial dysfunction are incompletely defined. However, one consistent finding from studies of experimental HHcy is impairment of vasodilation mediated by endothelium-derived nitric oxide. ${ }^{39}$ Nitric oxide is a potent vasodilator that is produced by the endothelial isoform of nitric oxide synthase (eNOS) in response to physiological stimuli, and is a major mediator of endothelium-dependent relaxation. ${ }^{37}$ Expression of eNOS does not appear to be decreased during HHcy, and vasodilator responses to nitroprusside or nitroglycerin are preserved, suggesting that sensitivity of vascular muscle to nitric oxide is relatively normal. ${ }^{41}$ It is likely, therefore, that $\mathrm{HHcy}$ decreases nitric oxide bioavailability through alternative mechanisms, such as accelerated oxidative inactivation of nitric oxide. ${ }^{40}$

Homocysteine-induced oxidative inactivation of nitric oxide has been observed in vitro in cultured endothelial cells, ${ }^{42}$ and evidence for increased oxidative inactivation of nitric oxide during $\mathrm{HHcy}$ has been obtained in animals using both pharmacological ${ }^{41,43-46}$ and genetic ${ }^{47,48}$ approaches. Several types of reactive oxygen species (ROS), including superoxide, hydrogen peroxide, and peroxynitrite, may contribute to the oxidative inactivation of endothelium-derived nitric oxide in HHcy. ${ }^{40}$

Another potential mechanism for endothelial dysfunction during $\mathrm{HHcy}$ is inhibition of nitric oxide production caused by asymmetric dimethylarginine (ADMA), an endogenous eNOS 
inhibitor. Elevated plasma levels of ADMA have been demonstrated in a non-human primate model of HHcy. ${ }^{49}$ In human subjects, plasma levels of ADMA increase rapidly after acute methionine loading and elevation of plasma ADMA correlates with impairment of endothelium-dependent relaxation. ${ }^{50}$ Elevation of ADMA in HHcy may be caused by decreased catabolism of ADMA by dimethylarginine dimethylaminohydrolases (DDAH), which hydrolyzes ADMA to citrulline and methylamines. ${ }^{51}$

Although recent experimental work on homocysteineinduced endothelial dysfunction has focused on the role of nitric oxide and oxidative stress, it should be recognized that homocysteine has several other properties that may adversely affect the endothelium. Homocysteine induces ER stress, ${ }^{52-56}$ stimulates proinflammatory responses, ${ }^{57}$ and alters the methylation of regulatory proteins such as Ras; ${ }^{58}$ each of these effects may result in activation of endothelial cell death pathways. Delineating the role of these potential mechanisms in producing endothelial dysfunction should be a priority for future studies.

\section{HHcy and Atherothrombosis: Potential Cellular Mechanisms}

\section{Inflammation}

Atherothrombotic disease is considered to be a form of chronic inflammation. ${ }^{1-3}$ Cell culture studies have demonstrated that homocysteine induces the production of several proinflammatory cytokines. Treatment of cultured human vascular endothelial cells, smooth muscle cells, and monocytes with homocysteine induces the expression of monocyte chemoattractant protein 1 (MCP-1). ${ }^{59-61} \mathrm{MCP}-1$ enhances the binding of monocytes to the endothelium and their recruitment to the subendothelial cell space, a critical step in atherosclerotic lesion development. Homocysteine has also been shown to increase expression of IL-8, ${ }^{59}$ a T lymphocyte and neutrophil chemoattractant, in cultured endothelial cells. Homocysteine-induced expression of MCP-1 and IL-8 has been shown to occur through activation of $\mathrm{NF}-\kappa \mathrm{B}$, a transcription factor known to stimulate the production of cytokines, chemokines, leukocyte adhesion molecules, and hemopoetic growth factors - all of which are thought to contribute to vascular inflammation and atherogenesis. ${ }^{1-3}$ The recent observations that $\mathrm{NF}-\kappa \mathrm{B}$ activation and downstream proinflammatory mediators and cytokines are increased in atherosclerotic lesions from hyperhomocysteinemic apolipoprotein E-deficient mice m,62 $^{28,6}$ urther supports the concept that $\mathrm{HHcy}$ accelerates atherogenesis by causing vascular inflammation.

\section{Oxidative stress}

The highly reactive thiol group of homocysteine is readily oxidized to form ROS, ${ }^{42}$ suggesting that homocysteine induces cell injury/dysfunction through a mechanism involving auto-oxidation and oxidative damage. However, this hypothesis fails to explain why cysteine, which is present in plasma at much higher concentrations than homocysteine and is readily auto-oxidized, does not cause endothelial cell injury and is not considered a risk factor for cardiovascular disease. ${ }^{63}$ Recent studies have also demonstrated that homocysteine is largely involved in antioxidant and reductive cellular biochemistry. ${ }^{64}$ In fact, the homocysteine-dependent transsulfuration pathway is critical in the maintenance of the intracellular glutathione pools, and the regulation of this pathway is sensitive to oxidative stress conditions. ${ }^{65,66}$

Homocysteine-induced oxidative stress may impact atherogenesis by mechanisms unrelated to auto-oxidation. Various ex vivo studies using vascular tissues have implicated $\mathrm{HHcy}$ in causing abnormal vascular relaxation responses by inducing the intracellular production of superoxide. ${ }^{67-69}$ Superoxide is believed to react with endothelial nitric oxide to yield peroxynitrite, thereby limiting the normal vasodilation response. ${ }^{70,71}$ Both superoxide and peroxynitrite contribute to the modification of tissues, resulting in the generation of lipid peroxides and in the case of peroxynitrite, the modification of proteins by tyrosine nitration and the formation of 3nitrotyrosine. The recent findings that heme oxygenase-1 (HO-1) and glutathione peroxidase (GPx) expression and activity are impaired in cultured vascular endothelial cells treated with homocysteine suggest that HHcy can inhibit the antioxidant potential of cells. ${ }^{48,52,72}$ This is particularly relevant to atherothrombosis given that (i) HHcy increases vascular dysfunction in GPx-deficient mice, ${ }^{48}$ (ii) overexpression of GPx attenuates homocysteine-induced endothelial dysfunction, ${ }^{47}$ and (iii) overexpression of $\mathrm{HO}-1$ inhibits the development of atherosclerosis in apoE ${ }^{-/-}$mice. $^{73}$

\section{Endoplasmic reticulum (ER) stress and the unfolded protein response (UPR)}

In eukaryotic cells, the ER is the principal site for folding and maturation of transmembrane, secretory, and ER-resident proteins. ${ }^{74-78}$ To assist in the correct folding of newly synthesized proteins and to prevent aggregation of folding intermediates, the ER contains numerous molecular chaperones such as GRP78, GRP94, calnexin, calreticulin, and protein disulfide isomerase. These chaperones act as a quality control system by ensuring that only correctly folded proteins are processed prior to entering the Golgi for further processing and secretion. Pathological conditions and/or agents that interfere with proper folding and maturation of proteins activate the UPR, an integrated intracellular signaling pathway that responds to ER stress by increasing the expression of UPR responsive genes (including the ERresident molecular chaperones), attenuating global protein translation and degrading unfolded proteins (Figure 2).

The UPR is mediated via the ER-resident sensors IRE-1, ATF-6, and PKR-like ER kinase (PERK), and activation of these sensors depends on their dissociation from GRP78 following ER stress. ${ }^{74-78}$ As a result, the UPR coordinately enhances cell survival by ensuring that the adverse effects of ER stress are dealt with in a timely and efficient manner. Failure to elicit a functional UPR as well as prolonged or severe ER stress can result in apoptotic cell death and contribute to the pathogenesis of a number of human diseases, including Alzheimer's disease, Parkinson's disease, and diabetes. ${ }^{76,77}$ 


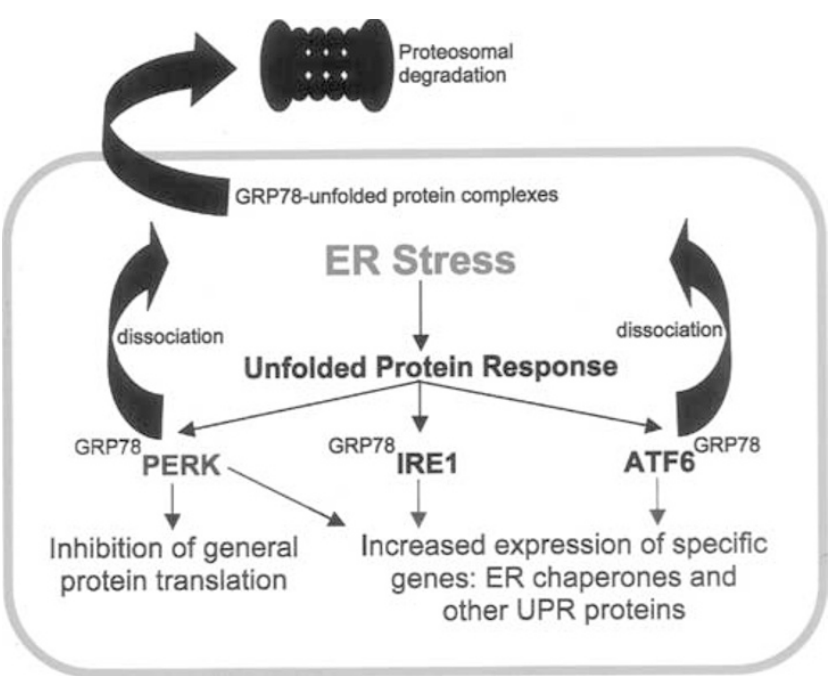

Figure 2 ER stress and the unfolded protein response (UPR). The UPR is regulated in eukaryotes by the proximal sensors IRE-1, ATF-6, and PERK. Activation of these sensors occurs following their dissociation from GRP78 in response to ER stress. Once activated, the UPR functions as an integrated, intracellular signaling pathway to attenuate protein translation, increase ER chaperone expression, and enhance degradation of unfolded proteins via the proteosome

One proposed mechanism of vascular injury by homocysteine involves ER stress and activation of the UPR. ${ }^{52-56,78}$ We as well as others have reported that elevated levels of intracellular homocysteine elicit ER stress, thereby leading to activation of the UPR and increased expression of ER stress response genes, including GRP78, GRP94, Herp, and RTP. ${ }^{52-56}$ In addition, homocysteine induces the expression of growth arrest- and DNA damage-inducible gene 153 $(\text { GADD153) })^{79}$ and T-cell death-associated gene 51 (TDAG51), ${ }^{22}$ proapoptotic factors induced by ER stress. These effects in gene expression directly involve the UPR because homocysteine treatment has been shown to induce the activation of both PERK ${ }^{80,81}$ and IRE-1. ${ }^{23}$

Severe or prolonged ER stress elicited by homocysteine has been shown to activate several cellular functions involved in the development and progression of atherosclerosis, including dysregulation of lipid metabolism, apoptotic cell death, and inflammation. We as well as others have demonstrated recently that homocysteine-induced ER stress causes dysregulation of lipid biosynthesis in hepatocytes by activating the SREBPs, ${ }^{56,82}$ which are ER-resident transcription factors responsible for the induction of genes in the cholesterol/triglyceride biosynthesis and uptake pathways. ${ }^{83}$ Stable overexpression of GRP78, which protects cells from agents and/or conditions known to cause ER stress, inhibits homocysteine-induced cholesterol gene expression in cultured human cells, providing further support for an association between ER stress and lipid metabolism. ${ }^{56}$ Consistent with these findings, ER stress, increased expression of cholesterol biosynthetic genes, and hepatic steatosis were observed in mice with diet-induced HHcy. Further studies, however, are required to determine if this mechanism contributes to the atherogenic effect of HHcy.

\section{HHcy, ER Stress and Apoptotic Cell Death}

Recent studies have demonstrated that homocysteine induces apoptotic cell death in cultured human vascular endothelial cells through activation of the UPR. ${ }^{23}$ Apoptotic cell death was dependent on IRE-1 signaling and was also induced by other ER stress agents, including tunicamycin and thapsigargin. Homocysteine-induced IRE-1 activation causes a rapid and sustained activation of JNK protein kinases, ${ }^{84}$ a result consistent with the finding that activation of JNK by ER stress involves binding of IRE-1 to TRAF2. ${ }^{85}$ Since persistent JNK activation is associated with apoptotic cell death, ${ }^{86}$ these studies provide further support for a homocysteine-induced mechanism involving UPR-dependent apoptotic cell death. Furthermore, caspase-3 activation is essential for homocysteine-induced apoptotic cell death, a result consistent with the ability of homocysteine thiolactone, a cyclic thioester derivative of homocysteine, ${ }^{87}$ to induce apoptotic cell death in HL-60 cells. ${ }^{88}$ Although caspase-7 and/or caspase-12 activation have been implicated in the coupling of ER stress to apoptotic cell death, ${ }^{89-91}$ there are presently no reported studies examining the effect of homocysteine on the activation of these caspases. Given that apoptosis has been widely documented to occur in animal and human atherosclerotic lesions, and that apoptotic cell death and ER stress are increased in atherosclerotic lesions from mice fed hyperhomocysteinemic diets (Zhou and Austin, submitted), it is possible that homocysteine-induced ER stress could adversely affect the stability and/or thrombogenicity of atherosclerotic lesions.

\section{HHcy, TDAG51 and Detachment-Mediated Apoptotic Cell Death}

It has been reported that homocysteine induces endothelial cell detachment ${ }^{92}$ and causes apoptotic cell death via a detachment-mediated process. ${ }^{93,94}$ Treatment of primary trophoblast cells with pathophysiological levels of homocysteine resulted in cellular flattening and enlargement, extension of pseudopodia, and cellular vacuolization. ${ }^{93}$ Furthermore, homocysteine, but not cysteine, induced trophoblast apoptosis as measured by loss of adhesion, increased mitochondrial cytochrome $c$ release, and DNA cleavage. Similar results were also observed in a human histiocytic lymphoma cell line U937 treated with homocysteine..$^{94}$

We have recently demonstrated that TDAG51 is induced by homocysteine, causes apoptotic cell death by impairing cell adhesion, and contributes to the development of atherosclerosis in apoE-deficient mice with diet-induced $\mathrm{HHcy}{ }^{22}$ TDAG51 is a member of a novel pleckstrin homology-related gene family that consists of Ipl/Tssc and Tih. ${ }^{95}$ Sequence analysis has revealed that TDAG51 contains a central motif resembling a pleckstrin homology domain and several distinctive C-terminal proline-glutamine (PQ) and prolinehistidine $(\mathrm{PH})$ repeats. Given that proteins with plekstrin homology domains are important in cytoskeletal organization $^{96}$ and that $\mathrm{PQ} / \mathrm{PH}$ repeats can regulate transcription and/ or apoptotic cell death, ${ }^{97-99}$ it has been suggested that TDAG51 functions to regulate cytoskeletal integrity and/or to 
mediate apoptosis. ${ }^{100,101}$ Recent studies have demonstrated that decreased expression of TDAG51 in metastatic melanoma confers resistance to apoptosis. ${ }^{102}$ In contrast, constituitive overexpression of TDAG51 increases apoptotic sensitivity and impairs melanoma cell proliferation. However, the precise mechanism by which TDAG51 mediates apoptotic cell death is not known. Although TDAG51 has been shown in vitro to play critical roles in the upregulation of Fas gene expression and activation-induced apoptosis of $\mathrm{T}$ cells, ${ }^{100}$ TDAG51-deficient mice express normal levels of Fas with no impairment in T-cell apoptosis. ${ }^{103}$ Furthermore, TDAG51 fails to increase Fas expression and does not promote Fasdependent apoptotic cell death in rat $\mathrm{H} 19-7$ neuronal cells. ${ }^{101}$ Based on these reports, there is no clear evidence implicating TDAG51 in the Fas-dependent cell death pathway. However, our findings that overexpression of TDAG51 leads to dramatic alterations in cell shape and increases detachment of cells from their appropriate matrix ${ }^{22}$ support a mechanism involving detachment-induced apoptosis or anoikis. Furthermore, the observation that TDAG51-induced shape changes are independent of caspase activation and occur prior to activation of the cell death program is consistent with this mechanism. ${ }^{22}$ Given that TDAG51 colocalizes with focal adhesion kinase and disrupts the actin cytoskeleton, ${ }^{22}$ it is conceivable that TDAG51 acts to impair focal adhesion complex assembly and attenuate survival signaling from the extracellular matrix prior to initiation of apoptosis.

In addition to its ability to decrease cell growth and promote apoptotic cell death, TDAG51 has been reported to inhibit protein synthesis, possibly by interacting with cellular factors involved in the regulation of protein translation. ${ }^{104}$ It is well established that activation of the UPR by ER stress leads to decreased rates of protein synthesis, ${ }^{105}$ a process mediated by the ER-resident kinase, PERK. ${ }^{106-108}$ Once activated, PERK phosphorylates Ser51 of eukaryotic initiation factor- $2 \alpha$ $($ elF2 $\alpha$ ), thereby inhibiting cellular mRNA translation and inducing transcriptional activation of a wide range of ER stress-inducible genes, including GRP78, GADD153, and TDAG51. ${ }^{106}$ Given that homocysteine causes ER stress, the ability of homocysteine to increase TDAG51 expression, activate PERK, ${ }^{80,81}$ and induce elF $2 \alpha$ phosphorylation ${ }^{80}$ is not surprising. Although these studies provide evidence that TDAG51 plays a role in protein translation, cell growth, cytoskeletal organization, and apoptotic cell death, its physiological function and role in atherothrombotic disease remain to be determined.

\section{Animal Models of HHcy-induced Atherogenesis}

Supplementation of methionine, homocysteine, and/or depletion of $B$ vitamins and folic acid in the diet can induce mild to severe HHcy. ${ }^{25-28}$ Transgenic mice deficient in CBS or MTHFR have also been used as animal models of HHcy. Homozygous CBS-deficient mice have total plasma homocysteine levels 40-fold greater than normal and suffer from severe growth retardation, hepatic steatosis, and dislocation of the lens ${ }^{109}$ - phenotypic changes also observed in human patients with homocystinuria. ${ }^{16-21}$ Heterozygous CBS-defi- cient mice have twice the normal concentration of total plasma homocysteine, but do not present with the same developmental defects observed in homozygotes, thereby making them ideal models to study mild HHcy. Heterozygous CBSdeficient mice develop endothelial dysfunction by decreasing vascular nitric oxide bioavailability, thereby leading to impaired vasorelaxation. ${ }^{41,46}$ This association is not unique to CBS-deficient mice, as endothelial dysfunction has also been observed in other animal models of HHcy, including rabbits and monkeys. ${ }^{67,110-113}$ Although CBS-deficient mice or non-murine models of $\mathrm{HHcy}$ exhibit endothelial dysfunction, there is no evidence of atherosclerotic lesion development. ${ }^{111-113}$

MTHFR-deficient mice share a similar phenotype with CBSdeficient mice but may be more prone to developing atherosclerosis. ${ }^{114}$ Adult heterozygous and homozygous MTHFR-deficient mice show aortic lipid accumulation that is reminiscent of early atherosclerotic lesions. Interestingly, plasma lipid levels are normal in these animals. Although the lipid accumulation is not as advanced as that observed in other murine models of atherosclerosis, including apoE- or LDL receptor-deficient mice, these observations are the first to show that mild HHcy contributes to athersclerotic lesion development.

Binding of monocytic cells to the vascular endothelium is one of the earliest detectable events in atherosclerotic lesion development. Recent studies have now demonstrated that the binding of monocytes to the endothelium is significantly elevated in rats with diet-induced $\mathrm{HHcy}$, although typical atherosclerotic lesions were not observed. ${ }^{115}$ The increased expression of MCP-1, VCAM-1, and E-selectin in the aortic endothelium of hyperhomocysteinemic rats suggests a potential cellular mechanism responsible for the enhanced monocyte binding and recruitment. The additional observation that supplementation of the diets with folic acid prevented an increase in total plasma homocysteine levels, decreased monocyte binding to the endothelium, and inhibited the expression MCP-1, VCAM-1, and E-selectin further supports an antiatherogenic effect of lowering plasma homocysteine.

Since atherosclerotic lesion development is limited in most animal models of $\mathrm{HHcy}$, we and other researchers have generated dietary $\mathrm{HHcy}$ in genetically altered mice prone to developing atherosclerosis. Several recent studies have demonstrated that mild HHcy accelerates atherogenesis in apoE-deficient mice. ${ }^{25-28}$ Zhou et a ${ }^{25,26}$ demonstrated that apoE-deficient mice fed chow diets supplemented with either methionine or homocysteine developed larger, more complex and more numerous arterial lesions, compared to mice fed control diets (Figure 3). Lesions were rich in smooth muscle cells and collagen, a result consistent with the ability of homocysteine to stimulate SMC proliferation and extracellular matrix deposition. ${ }^{116}$ The effects of the hyperhomocysteinemic diets on lesion size and frequency were seen following 3 months, but not 12 months, of dietary treatment, suggesting that HHcy mainly influences the early stages of atherogenesis. Hoffman et $a^{28}$ also found significant increases in atherosclerotic lesion area in apoE-deficient mice fed a high methionine diet, compared to mice fed control diet. Furthermore, HHcy was associated with an increase in $\mathrm{NF}-\kappa \mathrm{B}$ activation in aortic tissue, leading to the increased expression 

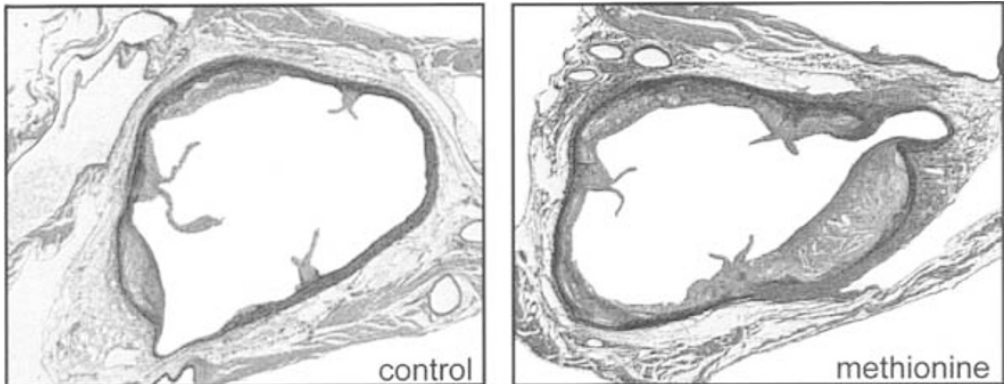

Figure 3 Atherosclerotic lesions in the aortic root of apoE-deficient mice fed a control diet or a high methionine diet to induce HHcy. Lesion sizes in mice fed high methionine diet were significantly larger, compared to mice fed control diet. Sections were stained with Orcein to reveal the elastic lamina (kindly provided by Ji Zhou and Erling Falk)

of the proinflammatory adhesion molecule VCAM-1 and the proinflammatory mediators RAGE and EN-RAGE. As discussed previously, the ability of homocysteine to activate NF$\kappa \mathrm{B}$ and enhance vascular inflammatory processes may in part be related to its ability to cause ER stress. Our finding that ER stress and NF- $\kappa \mathrm{B}$ activation are increased in the atherosclerotic lesions of mice with diet-induced HHcy provides support for this concept. ${ }^{62}$ A recent study by Wang et $a^{{ }^{7}}$ has also shown that genetic hyperhomocysteimia in a hyperlipidemic background accelerates atherosclerosis. Using compound apoE and CBS double knockout mice, atherosclerotic lesion area and lipid content increased with total plasma homocysteine concentrations, independent of diet.

In addition to its effects on atherogenesis, diet-induced hyperhomocysteimia in apoE-deficient mice increases the expression of tissue factor (TF), ${ }^{28}$ an integral membrane glycoprotein essential for the initiation of blood coagulation. ${ }^{117}$ Consistent with these findings, in vitro studies have shown that homocysteine can induce TF procoagulant activity. ${ }^{118}$ Evidence now indicates that an increase in TF expression and/or activity can enhance thrombin generation, thereby increasing lesion thrombogenicity and the risk of thrombotic complications. ${ }^{1,119,120}$ Thus, an increase in TF expression and/or activity has the potential to enhance thrombosis. Our recent findings that overexpression of GRP78 inhibits TF procoagulant activity ${ }^{121}$ suggest that inhibition of ER stress has the potential to suppress the prothrombotic potential of cells.

Collectively, these animal models of HHcy have supported and extended many of the proposed in vitro mechanisms and provide a physiological perspective on the role of $\mathrm{HHcy}$ in atherosclerotic lesion development. Although these studies demonstrate that HHcy accelerates atherogenesis when combined with hyperlipidemia, additional studies will be necessary to determine if HHcy accelerates atherogenesis in the presence of other cardiovascular risk factors, including diabetes and hypertension.

\section{Conclusions and Questions}

$\mathrm{HHcy}$ is an independent risk factor for cardiovascular disease. Several cellular mechanisms have been proposed to explain the effects of HHcy on endothelial dysfunction and atherosclerosis, including induction of proinflammatory factors, oxidative stress, and ER stress. Animal models of HHcy have demonstrated a causal relationship between HHcy, endothelial cell dysfunction, and accelerated atherosclerosis. These studies raise some interesting and relevant questions. Although HHcy accelerates early lesion development, what role does it play in plaque stability and/or thrombogenicity? Does HHcy, in the absence of hypercholesterolemia or other cardiovascular risk factors, enhance lesion development? Does dietary enrichment in B vitamins essential for the metabolism of homocysteine protect against cardiovascular disease? Do other risk factors such as hypercholestorlemia, diabetes, and/or hypertension contribute to atherothrombotic disease through a mechanism involving ER stress? This is particularly intriguing given that the accumulation of free cholesterol in the ER of cultured mouse peritoneal macrophages depletes ER calcium stores and leads to ER stress, UPR activation, and apoptotic cell death. ${ }^{122}$ Furthermore, an association between free cholesterol accumulation, apoptotic cell death, and markers of ER stress were reported in advanced atherosclerotic lesions from apoE-defcient mice. Answers to these and other important questions will undoubtedly enhance our understanding of the cellular mechanisms that mediate atherothrombotic disease and its clinical outcomes.

\section{Acknowledgements}

We thank Drs. J Zhou and J Dickhout for helpful comments during the preparation of this review. RC Austin is a Career Investigator of the Heart and Stroke Foundation of Ontario and is supported by Research Grants from the Heart and Stroke Foundation of Ontario (T-4005) and the Canadian Institutes of Health Research (MOP-49417). GH Werstuck is supported by a Research Grant from the Canadian Institutes of Health Research (MOP-62910). SR Lentz is supported in part by the Office of Research and Development, United States Department of Veterans Affairs, and National Institutes of Health Grants HL63943, NS24621, and HL62984. We apologize to many of our colleagues whose work could not be directly acknowledged due to space limitations.

\section{References}

1. Ross R (1999) Atherosclerosis - an inflammatory disease. N. Engl. J. Med. 340: 115-126

2. Fuster V (1994) Mechanisms leading to myocardial infarction: insight from studies of vascular biology. Circulation 90: 2126-2146 
3. Berliner JA, Navab M, Fogelman AM, Frank JS, Demer LL, Edwards PA, Watson AD and Lusis AJ (1995) Atherosclerosis: basic mechanisms. Oxidation, inflammation, and genetics. Circulation 91: 2488-2496

4. Navab M, Berliner JA, Watson AD, Hama SY, Territo MC, Lusis AJ, Shih DM, Van Lenten BJ, Frank JS, Demer LL, Edwards PA and Fogelman AM (1996) The Yin and Yang of oxidation in the development of the fatty streak. Arterioscler. Thromb. Vasc. Biol. 16: 831-842

5. Spady DK (1999) Reverse cholesterol transport and atherosclerosis regression. Circulation 100: 576-578

6. Stary HC, Chandler AB, Dinsmore RE, Fuster V, Glagov S, Insull Jr W, Rosenfeld ME, Schwartz CJ, Wagner WD and Wissler RW (1995) A definition of advanced types of atherosclerotic lesions and a histological classification of atherosclerosis. A report from the Committee on Vascular Lesions of the Council on Arteriosclerosis, American Heart Association. Circulation 92 1355-1374

7. Stary HC, Chandler AB, Glagov S, Guyton JR, Insull Jr W, Rosenfeld ME, Schaffer SA, Schwartz CJ, Wagner WD and Wissler RW (1994) A definition of initial, fatty streak, and intermediate lesions of atherosclerosis. A report from the Committee on Vascular Lesions of the Council on Arteriosclerosis, American Heart Association. Circulation 89: 2462-2478

8. Lee RT and Libby P (1997) The unstable atheroma. Arterioscler. Thromb. Vasc. Biol. 17: 1859-1867

9. Isner JM, Kearney M, Bortman S and Passeri J (1995) Apoptosis in human atherosclerosis and restenosis. Circulation 91: 2703-2711

10. Kockx MM, De Meyer GR, Muhring J, Bult H, Bultinck J and Herman AG (1996) Distribution of cell replication and apoptosis in atherosclerotic plaques of cholesterol-fed rabbits. Atherosclerosis 120: 115-124

11. Hegyi L, Skepper JN, Cary NR and Mitchinson MJ (1996) Foam cell apoptosis and the development of the lipid core of human atherosclerosis. J. Pathol. 180: 423-442

12. Tedgui $A$ and Mallat $Z$ (2001) Apoptosis as a determinant of atherosclerosis. Thromb. Haemost. 86: 420-426

13. Bennet MR (1999) Apoptosis of vascular smooth muscle cells in vascular remodeling and atherosclerotic plaque rupture. Cardiovasc. Res. 41: 361-368

14. Clarke R, Daly L, Robinson K, Naughten E, Cahalane S, Fowler B and Graham I (1991) Hyperhomocysteinemia: an independent risk factor for vascular disease. N. Engl. J. Med. 324: 1149-1155

15. den Heijer M, Koster T, Blom HJ, Bos GM, Briet E, Reitsma $P H$, Vandenbroucke JP and Rosendaal FR (1996) Hyperhomocysteinemia as a risk factor for deep-vein thrombosis. N. Engl. J. Med. 334: 759-762

16. McCully KS (1996) Homocysteine and vascular disease. Nat. Med. 2: 386389

17. Mudd SH, Levy HL and Skovby F (1989) Disorders of transsulfuration In The Metabolic Basis for Inherited Disease Scriver CR, Beadet AL, Sly WS, Vallee D (eds) (New York, NY: McGraw-Hill)

18. Selhub J, Jacques PF, Bostom AG, D'Agostino RB, Wilson PW, Belanger AJ O'Leary DH, Wolf PA, Schaefer EJ and Rosenberg IH (1995) Association between plasma homocysteine concentrations and extracranial carotid-artery stenosis. N. Engl. J. Med. 332: 286-291

19. Ueland PM, Refsum H, Beresford SAA and Vollset SE (2000) The controversy over homocysteine and cardiovascular risk. Am. J. Clin. Nutr. 72: 324-332

20. Welch GN and Loscalzo JN (1998) Homocysteine and atherothrombosis. N Engl. J. Med. 338: 1042-1050

21. Wilcken DEL and Dudman NPB (1992) Homocystinuria and atherosclerosis In Molecular Genetics of Coronary Artery Disease; Candidate Genes and Process in Atherosclerosis. Monograms in Human Genetics Lusis AJ, Rotter JI, Sparkes RS (eds) (New York, NY: Karger)

22. Hossain GS, van Thienen JV, Werstuck GH, Zhou J, Sood SK, Dickhout JG de Koning AB, Tang D, Wu D, Falk E, Poddar R, Jacobsen DW, Zhang K Kaufman RJ and Austin RC (2003) TDAG51 is induced by homocysteine, promotes detachment-mediated programmed cell death, and contributes to the cevelopment of atherosclerosis in hyperhomocysteinemia. J. Biol. Chem. 278: 30317-30327

23. Zhang C, Cai Y, Adachi MT, Oshiro S, Aso T, Kaufman RJ and Kitajama S (2001) Homocysteine induces programmed cell death in human vascula endothelial cells through activation of the unfolded protein response. J. Biol. Chem. 276: 35867-35874

24. Buemi M, Marino D, Di Pasquale G, Floccari F, Ruello A, Aloisi C, Corica F, Senatore M, Romea A and Frisina N (2001) Effects of homocysteine on proliferation, necrosis and apoptosis of vascular smooth muscle cells in culture and influence of folic acid. Thromb. Res. 104: 207-213

25. Zhou J, Møller J, Danielsen CC, Bentzon J, Ravn HB, Austin RC and Falk E (2001) Hyperhomocysteinemia promotes the development of collagen-rich and stable plaques in apoE-deficient mice. Arterioscler. Thromb. Vasc. Biol. 21: $1470-1476$

26. Zhou J, Møller J, Ritskes-Hoitinga M, Larsen ML, Austin RC and Falk E (2003) Effects of vitamin supplementation and hyperhomocysteinemia on atherosclerosis in apoE-deficient mice. Atherosclerosis 168: 255-262

27. Wang $H$, Jiang $X$, Yang $F$, Gaubatz JW, Ma L, Magera MJ, Yang $X$, Berger PB, Durante W, Pownall HJ and Schafer Al (2003) Hyperhomocysteinemia accelerates atherosclerosis in cystathionine betasynthase and apolipoprotein $\mathrm{E}$ double knock-out mice with and without dietary perturbation. Blood 101: 3901-3907

28. Hofmann MA, Lalla E, Lu Y, Gleason MR, Wolf BM, Tanji N, Ferran Jr LJ, Kohl B, Rao V, Kisiel W, Stern DM and Schmidt AM (2001) Hyperhomocysteinemia enhances vascular inflammation and accelerates atherosclerosis in a murine model. J. Clin. Invest. 107: 675-683

29. Mudd SH, Havlik R, Levy HL, McKusick VA and Feinleib M (1982) Cardiovascular risk in heterozygotes for homocystinuria. Am. J. Hum. Genet. 34: 1018-1021

30. Ueland PM and Refsum H (1989) Plasma homocysteine, a risk factor for vascular disease: plasma levels in health, disease, and drug therapy. J. Lab. Clin. Med. 114: 473-501

31. McCully KS (1969) Vascular pathology of homocysteinemia: implications for the pathogenesis of arteriosclerosis. Am. J. Pathol. 56: 111-128

32. Frosst $P$, Blom HJ, Milos R, Goyette $P$, Sheppard CA, Matthews RG, Boers GJ, den Heijer M, Kluijtmans LA, van den Heuvel LP and Rozen R (1995) A candidate genetic risk factor for vascular disease: a common mutation in methylenetetrahydrofolate reductase. Nat. Genet. 10: 111-113

33. Goyette P, Sumner JS, Milos R, Duncan AM, Rosenblatt DS, Matthews RG and Rozen R (1994) Human methylenetetrahydrofolate reductase: isolation of CDNA, mapping and mutation identification. Nat. Genet. 7: 195-200

34. Rosenblatt DS (1989) Inherited disorders of folate transport and metabolism In The Metabolic Basis of Inherited Disease 6th edn. Scriver CR, Beaudet AL, Sly WS, Valle D (eds) (New York, NY: McGraw-Hill)

35. Franken DG, Boers GHJ, Blom HJ, Trijibels FJM and Kloppenborg PW (1994) Treatment of mild hyperhomocysteinemia in vascular disease patients. Arterioscler. Thromb. 14: 465-470

36. Selhub J, Jacques PF, Wilson PWF, Rush D and Rosenberg IH (2001) Vitamin status and intake as primary determinants of homocysteinemia in an elderly population. J. Am. Med. Assoc. 270: 2693-2698

37. Cai $\mathrm{H}$ and Harrison DG (2000) Endothelial dysfunction in cardiovascular diseases: the role of oxidant stress. Circ. Res. 87: 840-844

38. Schachinger V, Britten MB and Zeiher AM (2000) Prognostic impact of coronary vasodilator dysfunction on adverse long-term outcome of coronary heart disease. Circulation 101: 1899-1906

39. Lentz SR (2001) Homocysteine and cardiovascular physiology In Homocysteine in Health and Disease Carmel R, Jacobsen DW (eds) (Cambridge, UK: Cambridge University Press)

40. Faraci FM and Lentz SR (2004) Hyperhomocysteinemia, oxidative stress, and cerebral vascular dysfunction. Stroke 35: 345-347

41. Eberhardt RT, Forgione MA, Cap A, Leopold JA, Rudd MA, Tolliet M, Heyrick S, Stark R, Klings ES, Moldovan NI, Yaghoubi M, Goldschmidt-Clermont PJ, Farber HW, Cohen R and Loscalzo J (2000) Endothelial dysfunction in a murine model of mild hyperhomocyst(e)inemia. J. Clin. Invest. 106: 483-491

42. Starkebaum G and Harlan JM (1986) Endothelial cell injury due to coppercatalyzed hydrogen peroxide generation from homocysteine. J. Clin. Invest. 77: 1370-1376

43. Kanani PM, Sinkey CA, Browning RL, Allaman M, Knapp HR and Haynes WG (1999) Role of oxidant stress in endothelial dysfunction produced by experimental hyperhomocyst(e)inemia in humans. Circulation 100: 11611168

44. Chambers JC, McGregor A, Jean-Marie J, Obeid OA and Kooner JS (1999) Demonstration of rapid onset vascular endothelial dysfunction after hyperhomocysteinemia. An effect reversible with vitamin $\mathrm{C}$ therapy. Circulation 99: 1156-1160

45. Ungvari Z, Csiszar A, Edwards JG, Kaminski PM, Wolin MS, Kaley G and Koller A (2003) Increased superoxide production in coronary arteries in 
hyperhomocysteinemia: role of tumor necrosis factor-alpha, $N A D(P) H$ oxidase, and inducible nitric oxide synthase. Arterioscler. Thromb. Vasc Biol. 23: 418-424

46. Weiss N, Heydrick S, Zhang YY, Bierl C, Cap A and Loscalzo J (2002) Cellular redox state and endothelial dysfunction in mildly hyperhomocysteinemic cystathionine beta-synthase-deficient mice. Arterioscler. Thromb. Vasc. Biol. 22: $34-41$

47. Weiss N, Zhang YY, Heydrick S, Bierl C and Loscalzo J (2001) Overexpression of cellular glutathione peroxidase rescues homocyst(e)ineinduced endothelial dysfunction. Proc. Natl. Acad. Sci. USA 98: 12503-12508

48. Dayal S, Brown KL, Weydert CJ, Oberley LW, Arning E, Bottiglieri T, Faraci FM and Lentz SR (2002) Deficiency of glutathione peroxidase-1 sensitizes hyperhomocysteinemic mice to endothelial dysfunction. Arterioscler. Thromb. Vasc. Biol. 22: 1996-2002

49. Böger RH, Bode-Böger SM, Sydow K, Heistad DD and Lentz SR (2000) Plasma concentration of asymmetric dimethylarginine, an endogenous inhibitor of nitric oxide synthase, is elevated in monkeys with hyperhomocyst(e)inemia or hypercholesterolemia. Arterioscler. Thromb. Vasc. Biol. 20: 1557-1564

50. Böger RH, Lentz SR, Bode-Böger SM, Knapp HR and Haynes WG (2001) Elevation of asymmetric dimethylarginine may mediate endothelial dysfunction during experimental hyperhomocyst(e)inemia in humans. Clin. Sci. 100: 161-167

51. Stuhlinger MC, Oka RK, Graf EE, Schmolzer I, Upson BM, Kapoor O, Szuba A, Malinow MR, Wascher TC, Pachinger $O$ and Cooke JP (2003) Endothelial dysfunction induced by hyperhomocyst(e)inemia: role of asymmetric dimethylarginine. Circulation 108: 933-938

52. Outinen PA, Sood SK, Pfeifer SI, Pamidi S, Podor TJ, Li J, Weitz JI and Austin RC (1999) Homocysteine-induced endoplasmic reticulum stress and growth arrest leads to specific changes in gene expression in human vascular endothelial cells. Blood 94: 959-967

53. Outinen PA, Sood SK, Liaw PC, Sarge KD, Maeda N, Hirsh J, Ribau J, Podor TJ, Weitz JI and Austin RC (1998) Characterization of the stress-inducing effects of homocysteine. Biochem. J. 332: 213-221

54. Kokame K, Agarwala KL, Kato H and Miyata T (2000) Herp, a new ubiquitinlike membrane protein induced by endoplasmic reticulum stress. J. Biol. Chem. 275: 32846-32853

55. Kokame K, Kato H and Miyata T (1996) Homocysteine-respondent genes in vascular endothelial cells identified by differential display analysis. GRP78/BiP and novel genes. J. Biol. Chem. 271: 29659-29665

56. Werstuck GH, Lentz SR, Dayal S, Hossain GS, Sood SK, Shi YY, Zhou J, Maeda N, Krisans SK, Malinow MR and Austin RC (2001) Homocysteineinduced endoplasmic reticulum stress causes dysregulation of the cholesterol and fatty acid biosynthetic pathways. J. Clin. Invest. 107: 1263-1273

57. Ungvari Z, Csiszar A, Edwards JG, Kaminski PM, Wolin MS, Kaley G and Koller A (2003) Increased superoxide production in coronary arteries in hyperhomocysteinemia: role of tumor necrosis factor-alpha, $N A D(P) H$ oxidase, and inducible nitric oxide synthase. Arterioscl. Thromb. Vasc. Biol. 23: 418-424

58. Wang H, Yoshizumi M, Lai KH, Tsai JC, Perrella MA, Haber E and Lee ME (1997) Inhibition of growth and p21(ras) methylation in vascular endothelia cells by homocysteine but not cysteine. J. Biol. Chem. 272: 25380-25385

59. Poddar R, Sivasubramanian N, Dibello PM, Robinson K and Jacobsen D (2001) Homocysteine induces expression and secretion of monocyte chemoattractant protein-1 and interleukin-8 in human aortic endothelial cells: implications for vascular disease. Circulation 103: 2717-2723

60. Wang $G$ and $O K$ (2001) Homocysteine stimulates the expression of monocyte chemoattractant protein-1 receptor (CCR2) in human monocytes: possible involvement of oxygen free radicals. Biochem. J. 357: 233-240

61. Wang G, Siow YL and O K (2001) Homocysteine induces monocyte chemoattractant protein-1 expression by activating NF-kappa B in THP-1 macrophages. Am. J. Physiol. Heart Circ. Physiol. 280: H2840-H2847

62. Zhou J, Werstuck GH, Lhotak S, de Koning ABL, Sood SK, Hossain GS Moller J, Ritskes-Hoitinga M, Falk E, Dayal S, Lentz SR and Austin RC (2003) Association of multiple cellular stress pathways with accelerated atherosclerosis in hyperhomocysteinemic ApoE-deficient mice. Circulation (in press)

63. Jacobsen DW (2000) Hyperhomocysteinemia and oxidative stress: time for a reality check? TArterioscler Thromb. Vasc. Biol. 20: 1182-1184
64. Zappacosta B, Mordente A, Persichilli S, Minucci A, Carlino P, Martorana GE, Giardina B and De Sole P (2001) Is homocysteine a pro-oxidant? Free Rad. Res. 35: 499-505

65. Vitvitsky V, Mosharov E, Tritt M, Ataullakhanov F and Banerjee R (2003) Redox regulation of homocysteine-dependent glutathione synthesis. Redox Rep. 8: 57-63

66. Mosharov E, Cranford MR and Banerjee R (2000) The quantitatively important relationship between homocysteine metabolism and glutathione synthesis by the transsulfuration pathway and its regulation by redox changes. Biochemistry 39: 13005-13011

67. Lang D, Kredan MB, Moat SJ, Hussain SA, Powell CA, Bellamy MF, Powers HJ and Lewis MJ (2000) Homocysteine-induced inhibition of endotheliumdependent relaxation in rabbit aorta: role for superoxide anions. Arterioscler. Thromb. Vasc. Biol. 20: 422-427

68. Duan J, Murohara T, Ikeda H, Sasaki K, Shintani S, Akita T, Shimada T and Imaizumi T (2000) Hyperhomocysteinemia impairs angiogenesis in response to hindlimb ischemia. Arterioscler. Thromb. Vasc. Biol. 20: 2579-2585

69. Franken DG, Boers GHJ, Blom HJ, Trijibels FJM and Kloppenborg PW (1994) Treatment of mild hyperhomocysteinemia in vascular disease patients. Arterioscler. Thromb. 14: 465-470

70. Gryglewski RJ, Palmer RM and Moncada S (1986) Superoxide anion is involved in the breakdown of endothelium-derived vascular relaxing factor. Nature 320: 454-456

71. Heinecke JW, Rosen H, Suzuki LA and Chait A (1987) The role of sulfurcontaining amino acids in superoxide production and modification of low density lipoprotein by arterial smooth muscle cells. J. Biol. Chem. 262: 1009810103

72. Upchurch GR, Welch GN, Fabian AJ, Freedman JE, Johnson JL, Keaney JF and Loscalzo J (1997) Homocyst(e)ine decreases bioavailable nitric oxide by a mechanism involving glutathione peroxidase. J. Biol. Chem. 272: 1701217017

73. Juan SH, Lee TS, Tseng KW, Liou JY, Shyue SK, Wu KK and Chau LY (2001) Adenovirus-mediated heme oxygenase-1 gene transfer inhibits the development of atherosclerosis in apolipoprotein E-deficient mice. Circulation 104: 1519-1525

74. Ron D (2002) Translational control in the endoplasmic reticulum stress response. J. Clin. Invest. 110: 1383-1388

75. Lee AS (2001) The glucose-regulated proteins: stress induction and clinical applications. Trends Biochem. Sci. 26: 504-510

76. Kaufman RJ (2002) Orchestrating the unfolded protein response in health and disease. J. Clin. Invest. 110: 1389-1398

77. Rutkowski DT and Kaufman RJ (2004) A trip to the ER: coping with stress. Trends Cell Biol. 14: 20-28

78. de Koning ABL, Werstuck GH, Zhou J and Austin RC (2003) Hyperhomocysteinemia and its role in the development of atherosclerosis. Clin. Biochem. 36: 431-441

79. Zinszner H, Kuroda M, Wang XZ, Batchvarova N, Lightfoot RT, Remotti H, Stevens JL and Ron D (1998) CHOP is implicated in programmed cell death in response to impaired function of the endoplasmic reticulum. Genes Dev. 12: 982-995

80. Ma K, Vattem KM and Wek RC (2002) Dimerization and release of molecular chaperone inhibition facilitate activation of eukaryotic initiation factor-2 kinase in response to endoplasmic reticulum stress. J. Biol. Chem. 277: 1872818735

81. Nonaka $\mathrm{K}$, Tsujino $T$, Watari $Y$, Emoto $N$ and Yokoyama $M$ (2001) Taurine prevents the decrease in expression and secretion of extracellular superoxide dismutase induced by homocysteine: amelioration of homocysteine-induced endoplasmic reticulum stress by taurine. Circulation 104: 1165-1170

82. Ji C and Kaplowitz N (2003) Betaine decreases hyperhomocysteinemia, endoplasmic reticulum stress, and liver injury in alcohol-fed mice. Gastroenterology 124: 1488-1499

83. Horton JD, Goldstein JL and Brown MS (2002) SREBPs: activators of the complete program of cholesterol and fatty acid synthesis in the liver. J. Clin. Invest. 109: 1125-1131

84. Cai Y, Zhang C, Nawa T, Aso T, Tanaka M, Oshiro S, Ichijo H and Kitajima S (2000) Homocysteine-responsive ATF3 gene expression in human vascular endothelial cells: activation of c-Jun $\mathrm{NH}(2)$-terminal kinase and promoter response element. Blood 96: 2140-2148 
85. Urano F, Wang X, Bertolotti A, Zhang Y, Chung P, Harding HP and Ron D (2000) Coupling of stress in the ER to activation of JNK protein kinases by transmembrane protein kinase IRE1. Science 287: 664-666

86. Chen Y-T, Meyer CF and Tan TH (1996) Persistent activation of C-Jun Nterminal kinase 1 (JNK1) in gamma radiation-induced apoptosis. J. Biol. Chem. 271: 631-634

87. Jakubowski H (1997) Metabolism of homocysteine thiolactone in human cell cultures. Possible mechanism for pathological consequences of elevated homocysteine levels. J. Biol. Chem. 272: 1935-1942

88. Huang RFS, Huang SM, Lin BS, Wei JS and Liu T-Z (2001) Homocysteine thiolactone induces apoptotic DNA damage mediated by increased intracellular hydrogen peroxide and caspase 3 activation in HL-60 cells. Life Sci. 68: 2799-2811

89. Reddy RK, Mao C, Baumeister P, Austin RC, Kaufman RJ and Lee AS (2003) Endoplasmic reticulum chaperone protein GRP78 protects cells from apoptosis induced by topoisomerase inhibitors: role of ATP binding site in suppression of caspase-7 activation. J. Biol. Chem. 278: 20915-20924

90. Rao RV, Hermel E, Castro-Obregon S, del Rio G, Ellerby LM, Ellerby HM and Bredesen DE (2001) Coupling endoplasmic reticulum stress to the cell death program. Mechanism of caspase activation. J. Biol. Chem. 276: 33869-33874

91. Nakagawa T, Zhu H, Morishima N, Li E, Xu J, Yankner BA and Yuan J (2000) Caspase-12 mediates endoplasmic-reticulum-specific apoptosis and cytotoxicity by amyloid-beta. Nature 403: 98-103

92. Boot MJ, Steegers-Theunissen RPM, Poelmann RE, van Iperen $L$ and Gittenberger-de Groot AC (2004) Homocysteine induces endothelial cell detachment and vessel wall thickening during chick embryonic development. Circ. Res. 94: 542-549

93. Di Simone N, Maggiano N, Caliandro D, Riccardi P, Evangelista A, Carducci B and Caruso A (2003) Homocysteine induces trophoblast cell death with apoptotic features. Biol. Reprod. 69: 1129-1134

94. Hultberg B, Andersson A and Isaksson A (1995) Metabolism of homocysteine, its relation to the other cellular thiols and its mechanism of cell damage in a cell culture line (human histiocytic cell line U-937). Biochem. Biophys. Acta 1269: 6-12

95. Frank D, Mendelsohn CL, Ciccone E, Svensson K, Ohlsson R and Tycko B (1999) A novel pleckstrin homology-related gene family defined by $I p / T s s c 3$, TDAG51, and Tih1: tissue-specific expression, chromosomal location, and parental imprinting. Mamm. Genome 10: 1150-1159

96. Maffucci T and Falasca M (2001) Specificity in pleckstrin homology (PH) domain membrane targeting: a role for a phosphoinositide-protein cooperative mechanism. FEBS. Lett. 506: 173-179

97. McNabb DS and Courtney RJ (1992) Analysis of the UL36 open reading frame encoding the large tegument protein (ICP1/2) of herpes simplex virus type 1. J. Virol. 66: 7581-7584

98. Cai J, Lan Y, Appel LF and Weir M (1994) Dissection of the Drosophila paired protein: functional requirements for conserved motifs. Mech. Dev. 47: 139150

99. Li P, Allen H, Banerjee S, Franklin S, Herzog L, Johnston C, McDowell J, Paskind M, Rodman L and Salfeld J (1995) Mice deficient in IL-1betaconverting enzyme are defective in production of mature IL-1beta and resistant to endotoxic shock. Cell 80: 401-411

100. Park CG, Lee SY, Kandala G, Lee SY and Choi Y (1996) A novel gene product that couples TCR signalling to Fas(CD95) expression in activationinduced cell death. Immunity 4: 583-591

101. Gomes I, Xiong W, Miki T and Rosner MR (1999) A proline- and glutaminerich protein promotes apoptosis in neuronal cells. J. Neurochem. 73: 612-622

102. Neef R, Kuske MA, Prols $E$ and Johnson JP (2002) Identification of the human PHLDA1/TDAG51 gene: down-regulation in metastatic melanoma contributes to apoptosis resistance and growth deregulation. Cancer Res. 62: 5920-5929

103. Rho J, Gong S, Kim N and Choi Y (2001) TDAG51 is not essential for Fas/ CD95 regulation and apoptosis in vivo. Mol. Cell. Biol. 21: 8365-8370

104. Hinz T, Flindt S, Marx A, Janssen $O$ and Kabelitz D (2001) Inhibition of protein synthesis by the T cell receptor-inducible human TDAG51 gene product. Cell. Signal. 13: 345-352
105. Wong WL, Brostrom MA, Kuznetsov G, Gmitter-Yellen D and Brostrom CO (1993) Inhibition of protein synthesis and early protein processing by thapsigargin in cultured cells. Biochem. J. 289: 71-79

106. Scheuner D, Song B, McEwen E, Liu C, Laybutt R, Gillespie P, Saunders T, Bonner-Weir S and Kaufman RJ (2001) Translational control is required for the unfolded protein response and in vivo glucose homeostasis. Mol. Cell 7: $1165-1176$

107. Harding HP, Zhang $Y$ and Ron D (1999) Protein translation and folding are coupled by an endoplasmic-reticulum-resident kinase. Nature 397: 271-274

108. Harding HP, Zhang Y, Bertolotti A, Zeng H and Ron D (2000) Perk is essential for translational regulation and cell survival during the unfolded protein response. Mol. Cell 5: 897-904

109. Watanabe M, Osada J, Aratani Y, Kluckman K, Reddick R, Malinow MR and Maeda N (1995) Mice deficient in cystathionine beta-synthase: animal models for mild and severe homocyst(e)inemia. Proc. Natl. Acad. Sci. USA 92: 1585-1589

110. Ambrosi $P$, Rolland $P H$, Bodard $H$, Barlatier $A$, Charpiot $P$, Guisgand $G$ Friggi A, Ghiringhelli O, Habib G, Bouvenot G, Garcon D and Luccioni R (1999) Effects of folate supplementation in hyperhomocysteinemic pigs. J. Am. Coll. Cardiol. 34: 274-279

111. Lentz SR, Erger RA, Dayal S, Maeda N, Malinow MR, Heistad DD and Faraci FM (2000) Folate dependence of hyperhomocysteinemia and vascular dysfunction in cystathionine beta-synthase-deficient mice. Am. J. Physiol. Heart Circ. Physiol. 279: H970-H975

112. Lentz SR, Malinow MR, Piegors DJ, Bhopatkar-Teredesai M, Faraci FM and Heistad DD (1997) Consequences of hyperhomocyst(e)inemia on vascular function in atherosclerotic monkeys. Arterioscler. Thromb. Vasc. Biol. 17: 2930-2934

113. Lentz SR, Piegors DJ, Malinow RM and Heistad DD (2001) Supplementation of atherogenic diet with B vitamins does not prevent atherosclerosis or vascular dysfunction in monkeys. Circulation 103: 1006-1011

114. Chen Z, Karaplis AC, Ackerman SL, Pogribny IP, Melnyk S, Lussier-Cacan S, Chen MF, Pai A, John SW, Smith RS, Bottiglieri T, Bagley P, Selhub J, Rudnicki MA, James SJ and Rozen R (2001) Mice deficient in methylenetetrahydrofolate reductase exhibit hyperhomocysteinemia and decreased methylation capacity, with neuropathology and aortic lipid deposition. Hum. Mol. Genet. 10: 433-443

115. Wang G, Woo CWH, Sung FL, Siow YL and O K (2002) Increased monocyte adhesion to aortic endothelium in rats with hyperhomocysteinemia: role of chemokine and adhesion molecules. Arterioscler. Thromb. Vasc. Biol. 22: 1777-1783

116. Majors A, Ehrhart LA and Pezacka EH (1997) Homocysteine as a risk factor for vascular disease. Enhanced collagen production and accumulation by smooth muscle cells. Arterioscler. Thromb. Vasc. Biol. 17: 2074-2081

117. Nemerson $Y$ (1992) The tissue factor pathway of blood coagulation. Semin. Hematol. 29: 170-176

118. Fryer RH, Wilson BD, Gubler DB, Fitzgerald LA and Rodgers GM (1993) Homocysteine, a risk factor for premature vascular disease and thrombosis, induces tissue factor activity in endothelial cells. Arterioscler. Thromb. Vasc. Biol. 13: 1327-1333

119. Toschi V, Gallo G, Lettino M, Fallon JT, Gertz SD, Fernandez-Ortiz A, Chesebro JH, Badimon L, Nemerson Y, Fuster V and Badimon JJ (1997) Tissue factor modulates thrombogenecity of human atherosclerotic plaques. Circulation 95: 594-599

120. Ardissino D, Merlini PA, Ariens R, Coppola R, Bramucci E and Mannucci PM (1997) Tissue-factor antigen and activity in human coronary atherosclerotic plaques. Lancet 349: 769-771

121. Watson LM, Chan AK, Berry LR, Li J, Sood SK, Dickhout JG, Xu L, Werstuck GH, Bajzar L, Klamut HJ and Austin RC (2003) Overexpression of the 78-kDa glucose-regulated protein/immunoglobulin-binding protein (GRP78/BiP) inhibits tissue factor procoagulant activity. J. Biol. Chem. 278: 17438-17447

122. Feng B, Yao PM, Li Y, Devlin CM, Zhang D, Harding HP, Sweeney M, Rong JX, Kuriakose G, Fisher EA, Marks AR, Ron D and Tabas I (2003) The endoplasmic reticulum is the site of cholesterol-induced cytotoxicity in macrophages. Nat. Cell Biol. 5: 781-792 